\title{
AVALIAÇÃO DAS AVALIAÇÕES DE TEXTOS CIENTÍFICOS SOBRE CONTABILIDADE E CONTROLADORIA
}

\section{THE GOVERNMENTAL ACCOUNTANCY RULE-MAKING: CRITICAL FACTORS THAT SHOCK INFORMATION PROVIDED TO ACCOUNTING INFORMATION USERS}

\section{EVALUACIÓN DE LAS EVALUACIONES DE TEXTOS CIENTÍFICOS SOBRE CONTABILIDAD Y CONTRALORÍA}

\author{
DR. GILBERTO DE ANDRADE MARTINS \\ Universidade de São Paulo - USP \\ martins@usp.br
}

\section{RESUMO}

Não é possível negar: por mais cuidados que sejam observados no processo de avaliação de textos científicos, os pareceres e os resultados das avaliações sempre estarão atados ao conhecimento, à atitude, à habilidade e à ética do avaliador. Por mais que se busque a objetivação da avaliação jamais se conseguirá um resultado ideal - justo, com a plena concordância dos autores e do avaliador sobre todos os textos analisados. Todavia, mesmo considerando tais premissas, discussões sobre esse desafiador tema deve continuamente fazer parte da pauta dos programas de pósgraduação, das comissões científicas dos congressos, dos encontros, dos seminários, etc. e dos corpos editoriais dos periódicos de quaisquer áreas do conhecimento. Neste trabalho, procura-se discutir, explicar e apresentar uma avaliação das avaliações dos textos científicos aprovados e defendidos no $5^{\circ}$ Congresso USP de Controladoria e Contabilidade da FEA/USP. Foram analisados todos os 100 trabalhos aprovados, envolvendo 300 pareceres contendo avaliações quantitativas e notas a dez quesitos - e avaliações qualitativas - pontos fortes e fracos de cada texto. Setenta e cinco por cento dos pareceres foram extremamente favoráveis aos autores dos textos, tanto em 
relação às notas quanto em relação às avaliações qualitativas. Aproximadamente $65 \%$ das menções a pontos fortes, indicadores da aprovação dos textos, se resumiram à relevância do assunto-tema, da redação e da estruturação do trabalho. Essa elevada proporção indica que uma expressiva maioria de avaliações dos textos não se pautou pelo necessário rigor na avaliação de seus conteúdos. Os resultados mostraram extraordinárias dispersões entre avaliadores de mesmos textos e entre avaliadores de todos os textos submetidos e aprovados. A maioria dos pareceres é enunciada de maneira lacônica, sendo que muitos deles apresentam inconsistências internas e elevados graus de incompreensibilidade.

Palavras Chaves: Conhecimento. Avaliações. Indicadores. Contabilidade. Controladoria.

\section{ABSTRACT}

It is impossible to deny: whatever concerns that are observed in the scientific texts' evaluation process, the sentences and results of the evaluations always will be tied to the knowledge, the attitude, the ability and the ethics of the appraiser. No matter how hard you seek the evaluation's objectification, an ideal result will never be obtained - fair, with full agreement from the authors and the appraiser on all the analyzed texts. However, even considering such premises, discussions on this challenging subject must continuously take part on the guideline in postgraduate work programs, congresses' scientific commissions, meetings, seminaries, etc. and in periodics' publishing bodies in any area of knowledge. This work seeks to discuss, to explain and to present an analysis of the evaluations of the scientific texts approved and defended in the FEA/USP's 5th Controller and Accountancy USP Congress. The 100 approved works were analyzed, involving 300 sentences containing quantitative evaluations and grades to ten queries, and qualitative evaluations, strong and weak points of each text. Seventy five percent of the sentences were extremely favorable to the texts' authors, relating to grades as much as relating to the qualitative evaluations. Approximately $65 \%$ of the mentions to strong points, text approval indicators, represented the relevance of the subject-theme, the writing and the work's structure. This elevated ratio indicates that the texts' evaluations' expressive majority was not ruled with the necessary severity in its contents' evaluation. The results have shown extraordinary dispersions between appraisers of same texts and appraisers of all the submitted and approved texts. The sentences' majority is enunciated in a laconic way, such that many of them present internal inconsistencies and high degrees of incomprehensibility.

Keywords: Knowledge. Evaluations. Indicators. Accountancy. Controlling. 


\section{repec}

\section{RESUMEN}

No es posible negar: por más cuidados que sean observados en el proceso de evaluación de textos científicos, los pareceres y los resultados de las evaluaciones siempre estarán unidos al conocimiento, a la aptitud, a la habilidad y a la ética del evaluador. Por más que se busque la objetivación de la evaluación jamás se conseguirá un resultado ideal - justo, con la plena concordancia de los autores y del evaluador sobre todos los textos analizados. Aún, incluso considerando tales premisas, discusiones sobre ese desafiador tema debe continuamente hacer parte de la pauta de los programas de post graduación, de las comisiones científicas de los congresos, de los encuentros, de los seminarios, etc. y de los cuerpos editoriales de los periódicos de cualquier área del conocimiento. En este trabajo, se intenta discutir, explicar y presentar una evaluación de las evaluaciones de los textos científicos aprobados y defendidos en el $5^{\circ}$ Congreso Usp de Contraloría y Contabilidad de la FEA/USP. Fueron analizados todos los 100 trabajos aprobados, involucrando 300 pareceres conteniendo evaluaciones cuantitativas y anotaciones a diez apartados - y evaluaciones cualitativas - puntos Fuertes y flojos de cada texto. Setenta y cinco por ciento de los pareceres fueron extremadamente favorables a los autores de los textos, tanto con relación a las anotaciones como con relación a las evaluaciones cualitativas. Aproximadamente $65 \%$ de las menciones a puntos Fuertes, indicadores de la aprobación de los textos, se condensaron a la relevancia del asunto-tema, de la redacción y de la estructuración del trabajo. Esa elevada proporción indica que una expresiva mayoría de evaluaciones de los textos no se pautó por el necesario rigor en la evaluación de sus contenidos. Los resultados mostraron extraordinarias dispersiones entre evaluadores de los mismos textos y entre evaluadores de todos los textos sometidos y aprobados. La mayoría de los pareceres es enunciada de manera lacónica, siendo que muchos de ellos presentan inconsistencias internas y elevados grados de incomprensibilidad.

Palabras Clave: Conocimiento. Evaluaciones. Indicadores. Contabilidad. Contraloría.

\section{CONTEXTUALIZAÇÃO}

É inquestionável o crescimento da produção científica sobre Contabilidade e Controladoria nos últimos 10 anos. Multiplicaram-se os programas de pós-graduação stricto sensu, bem como se elevaram as ofertas de cursos de especialização (modalidade MBA). Foram criados novos seminários, encontros e congressos - espaços privilegiados para a apresentação e a discussão de textos científicos. Também se aumentou a quantidade de periódicos com linha editorial dedicada exclusivamente às Ciências Contábeis. Assim é que a publicação de teses, dissertações, monografias, artigos e trabalhos dirigidos a encontros científicos cresceram extraordinariamente, evidenciando-se, naturalmente, a necessária 
atenção à qualidade dessa produção. É dentro desse contexto que se propõe este estudo crítico-analítico sobre as avaliações de textos científicos, particularmente dos trabalhos submetidos e aprovados para o $5^{\circ}$ Congresso USP de Controladoria e Contabilidade, realizado em 2005 na FEA/USP.

No trabalho aqui relatado, empreendeu-se um estudo de caráter epistemológico da produção científica divulgada no referido Congresso, com a finalidade de levantar, caracterizar e analisar os pareceres dos avaliadores dos trabalhos aprovados e apresentados no referido evento. Esta proposta de pesquisa surge ante a necessidade de se compreender e explicar aspectos do polêmico processo de avaliação de textos científicos de quaisquer áreas do conhecimento, neste caso, dos campos da Controladoria e da Contabilidade.

A amplitude e as diversidades de temas, os problemas estudados, as diferentes alternativas para a construção das plataformas teóricas que possam sustentar o desenvolvimento do texto, as distintas abordagens metodológicas empreendidas, as variadas estratégias de pesquisa, a diversidade de técnicas e de instrumentos de coleta de dados, os diferentes approachs para tratamento e análise dos resultados e as conclusões impõem ao avaliador de textos científicos muita atenção, coerência, senso de justiça, e procedimentos claros e precisos pautados pela ética. Os desafios colocados para os avaliadores exigem compromissos e responsabilidades. Afinal, são centenas de autores que aguardam seus pareceres, esperando justiça e coerência nas decisões dos avaliadores.

A investigação aqui empreendida é uma atitude deliberada e sistemática de busca de explicações sobre possíveis critérios utilizados pelos avaliadores dos textos científicos defendidos nas sessões do referido Congresso. É amplo e complexo o debate sobre as condições e os critérios que determinam as opções dos avaliadores dos temas submetidos a um Congresso ou à editoria de um periódico. Este trabalho analisa um segmento particular dessa produção - avaliação das avaliações de trabalhos científicos - com intuito de contribuir para estudos auto-avaliativos sobre a produção científica, bem como oferecer elementos para uma reflexão crítica sobre a qualidade do que se está produzindo. Pretende-se chamar a atenção, levar a debate e apresentar sugestões para superação de possíveis insuficiências e vieses dessa produção no que se refere ao trabalho dos avaliadores de textos científicos.

Contribuições desta investigação, por certo, irão ajudar as discussões sobre essa fundamental problemática e, conseqüentemente, contribuir para a melhoria da qualidade da produção científica sobre Controladoria e Contabilidade. Os resultados desta pesquisa poderão ser úteis para os pesquisadores da área contábil: avaliadores de textos submetidos, particularmente aos autores de trabalhos, professores, enfim, aos interessados na produção científica deste pungente campo de conhecimento. 


\section{repec}

\section{PLATAFORMA TEÓRICA}

Em texto divulgado na seção Opinião (2005) do site da (Anpad) Associação Nacional dos Programas de Pós-Graduação em Administração o ex-diretor científico da entidade, Rogério H. Quintella (2005), escreveu sobre a "Ética e Sistematização da Avaliação de Trabalhos Científicos", entre outros comentários expõe suas conclusões:

1 - É Desejável Que Voltemos A Discutir A Avaliação Sistemática E Objetiva Do Trabalho Dos Pareceristas.

2 - Devemos Pensar, Tanto No Âmbito Da Anpad Como Fora Dela, Em Compensar Ou Premiar Bons Trabalhos De Avaliação.

3 - Não Devemos, Jamais, Esquecer E, Portanto, Sempre Compreender, Que Por Mais Elaborados Que Sejam Os Processos De Avaliação De Trabalhos Científicos, Os Resultados Das Avaliações, Deles Resultantes, Sempre Estarão Atados Ao Conhecimento, À Habilidade, À Atitude E À Ética De Seres HumanoS Pontualmente Travestidos Em Avaliadores De Trabalhos Científicos.

Ainda do texto do pesquisador Quintella (2005) são expressas cinco normas gerais de cunho técnico e moral: (a) o processo de avaliação deve ser duplamente anônimo - double blind review; (b) da avaliação de um trabalho devem participar dois pareceristas independentes e desconhecidos entre si; (c) havendo discordância de avaliação entre os dois avaliadores, o trabalho, desacompanhado dos pareceres, deveria ser encaminhado a um terceiro parecerista, igualmente anônimo; (d) no caso de haver objeções, críticas e pedidos de reformulações do conteúdo, o autor deverá ser ouvido; (e) o parecerista tem autonomia para recusar trabalhos pouco relacionados aos seus conhecimentos.

Entre as alternativas para aperfeiçoar o processo de avaliação, editorias de periódicos têm enviado a cada avaliador os pareceres de outros avaliadores sobre os mesmos textos. O conselho do ENANPAD, segundo Quintella (2005), tem tomado medidas, visando à melhoria das avaliações e, conseqüentemente, dos trabalhos aprovados:

- Rigor das avaliações do formato dos textos recebidos, reprovando aqueles trabalhos cujos autores não observaram as exigências divulgadas nas chamadas de trabalhos.

- Adoção de sistema informatizado que garante o anonimato dos autores e avaliadores.

- Busca de critérios objetivos para elaboração do parecer pela prática de escala numérica para avaliação de dez quesitos.

- Padronização das notas dos avaliadores, por meio do cálculo do escore Z, como forma de se atenuar as discrepâncias naturais entre avaliadores.

- Adoção de sistema informatizado que identifica para o coordenador avaliações muito discrepantes - diferença entre as médias maior ou igual a cinco. As notas para cada quesito variam de 0 a 10. 
- Avaliação dos avaliadores por parte dos coordenadores das áreas.

Com semelhante preocupação e interesse, a professora Maria José Tonelli, da FGVEAESP, participou, em 2004, de um encontro da Academy of Management, em Nova Orleans, anotando depoimentos de especialistas que integraram um painel com o título "The craft of reviewing". Eis alguns parâmetros para avaliadores de textos enviados para a publicação em periódicos:

- O trabalho do avaliador é de suma importância para a qualidade do artigo: deve ser feito com tanto rigor quanto o trabalho do próprio autor.

- Prepare-se para vários ciclos de avaliação. Grande parte dos trabalhos científicos passa ao menos por 2 a 3 ciclos. O primeiro ciclo deve ser mais extenso e detalhado. Os demais podem ser mais breves e objetivos.

- Evite rejeitar um trabalho sem dar justificativas plausíveis e claras. Faça sempre uma revisão completa. Ela certamente será útil para o autor e alimentará um ciclo virtuoso.

- Foque sua revisão em questões mais críticas e explique-as detalhadamente.

- Seja claro em relação aos métodos que considera mais adequados para serem aplicados.

- Inclua referências bibliográficas sempre que possível.

- Identifique pontos de atenção e procure oferecer uma lista de soluções.

- Evite dar sugestões genéricas. Esclareça suas posições e mostre evidências.

- Procure sempre usar um tom construtivo.

- Evite comentários de base ideológica ou que impliquem juízo de valores.

\section{TRAJETÓRIA METODOLÓGICA}

Em função dos propósitos do estudo, foi adotada uma abordagem metodológica empírico-analítica com levantamento censitário das 300 avaliações dos trabalhos submetidos e aprovados para o $5^{\circ}$ Congresso USP de Controladoria e Contabilidade, ocorrido em 2005. Foram empreendidas avaliações quantitativas e qualitativas das planilhas de todos os avaliadores, com cálculos das estatísticas descritivas das notas atribuídas a dez quesitos para cada artigo e cada avaliador, bem como análises dos conteúdos dos breves textos em que o avaliador informava pontos negativos e positivos do trabalho analisado. O Quadro 1, a seguir, mostra as dimensões que foram avaliadas pela atribuição de notas entre 1 e 5. 


\section{Quadro 1 - Dimensões Avaliativas - 5 Congresso USP de Controladoria e Contabilidade - 2005}

\begin{tabular}{|r|l|}
\hline$\#$ & Quesito \\
\hline $\mathbf{1}$ & O tema é atual, relevante e oportuno. \\
\hline $\mathbf{2}$ & O resumo evidencia claramente o conteúdo do artigo. \\
\hline $\mathbf{3}$ & O objetivo do artigo está claro e bem definido. \\
\hline $\mathbf{4}$ & $\begin{array}{l}\text { A base teórico-conceitual é consistente e reflete o estado-arte do conhecimento } \\
\text { na área. }\end{array}$ \\
\hline $\mathbf{5}$ & O referencial teórico é adequado e bem estruturado. \\
\hline $\mathbf{6}$ & $\begin{array}{l}\text { O objeto de pesquisa e a metodologia estão claramente delineados e adequados } \\
\text { aos objetivos do trabalho. }\end{array}$ \\
\hline $\mathbf{7}$ & Os resultados apresentados respondem aos objetivos do artigo. \\
\hline $\mathbf{8}$ & A conclusão é coerente, clara e objetiva. \\
\hline $\mathbf{9}$ & A bibliografia apresentada é coerente com a temática estudada. \\
\hline $\mathbf{1 0}$ & $\begin{array}{l}\text { O trabalho representa uma contribuição científica para o conhecimento em Con- } \\
\text { troladoria e Contabilidade e/ou para a prática nesta área do conhecimento. }\end{array}$ \\
\hline
\end{tabular}

A representatividade desse conjunto de trabalhos científicos do universo das Ciências Contábeis foi garantida vez que o Congresso USP expressa o mais importante evento científico nacional da área, que para esse encontro recebeu 474 trabalhos. Assim é que foram avaliadas as avaliações de 18 trabalhos da área temática de Contabilidade Aplicada para Usuários Externos; 23 da área de Controladoria e Contabilidade Gerencial; 23 sobre Mercados Financeiros de Crédito e de Capitais; 2 sobre Pesquisa e Ensino da Contabilidade e 34 da área temática sobre assuntos emergentes em Contabilidade.

\section{SOBRE OS ACHADOS}

A análise dos resultados foi dividida em três partes: resultados decorrentes das avaliações qualitativas dos pareceristas, análises das avaliações quantitativas e comparações entre essas duas avaliações.

\subsection{Avaliações qualitativas}

Os pareceristas foram solicitados a expressarem pontos fortes e pontos fracos dos textos submetidos e, no contexto deste trabalho, artigos aprovados. Evidenciando pouca criatividade, um expressivo número de pareceristas declarou 133 menções - 44\% do total de 300 -, indicando a aceitação de textos e expressando como pontos fortes, unicamente, a "relevância, atualidade, importância ou o interesse do assunto, tema ou problema da pesquisa". Na mesma linha sintética de avaliação, $11 \%$ dos pareceres indicaram como 
pontos fortes a 'boa redação do artigo'. Um dos pareceres sobre pontos fortes ilustra o que acima foi dito: "O trabalho está bem escrito". Em contrapartida, proporção assemeIhada de avaliações - 13\% - declararam que pontos fracos dos textos estavam relacionados à redação - 'mistura de tempos verbais; concordância verbal e nominal; falta de clareza; linguagem, etc'.

Reduzir a avaliação de um trabalho científico unicamente a considerações sobre gramática e linguagem, ou afirmar a importância do assunto-tema, muito pouco se contribui para com o autor e, tampouco, para a necessária melhoria da qualidade dos trabalhos científicos sobre Controladoria e Contabilidade.

Foram encontradas 108 menções positivas à metodologia adotada pelos autores. Ressalte-se que muitas indicações de pontos fortes foram evidenciadas pela prática de "pesquisas empíricas", reforçando resultados de estudos que apontam o forte crescimento de investigações empíricas sobre o universo contábil. Dentro desse reconhecimento sobre a importância da metodologia, $12 \%$ dos pontos fortes identificados reportaram-se ao uso de métodos quantitativos, particularmente métodos e técnicas estatísticas.

As estruturações dos trabalhos - edição, formatação, organização, adequação às normas da ABNT, etc. - foram elementos que apareceram nos pontos fortes e também nos pontos fracos - 10\% e 18\% respectivamente. Sintetizando: aproximadamente $65 \%$ das menções a pontos fortes, indicadores da aprovação dos textos, se resumiram à relevância do assunto-tema, da redação e da estruturação do trabalho. Essa elevada proporção indica, claramente, que uma expressiva maioria de avaliações dos textos, aprovados para o $5^{\circ}$ Congresso, não se pautou pelo necessário rigor na avaliação de seus conteúdos. A maioria dos trabalhos foi aprovada por critérios obrigatórios para qualquer texto que se pretenda científico: importância, redação e estruturação.

As transcrições a seguir ilustram pontos fortes declarados por lacônicos pareceres. Evidenciam contradições, imprecisões e inconsistências gritantes:

"Penso que não contribuiu muito".

"Bom, apesar de incompleto (...)".

"Tabelas bem feitas".

"Na atual conjuntura o tema é atual".

"Trabalho de excepcional qualidade".

"Muito bom, sem pontos fracos".

"Razoavelmente bem elaborado".

"Os casos são interessantes".

Reforçando evidências do pouco compromisso dos avaliadores em relação aos pareceres solicitados, a seguir, estão elencados mais exemplos de contradições e mensagens inteligíveis: 
"Pontos fortes: não-identificados. O trabalho pode ser aceito".

"O estudo de caso é limitado a uma empresa".

"Não há, a meu ver, qualidades que possam ser evidenciadas (...). Trabalho pode ser aceito".

"Pontos fortes: qualidade do resumo".

"Pontos fortes: não há. Pontos fracos: assunto 'batido' sem novidades, mal escrito. Trabalho deve ser aceito".

"Pontos fortes: a análise dos retornos com e sem fusões acrescenta visões a esse debate".

Aparentemente, um dos avaliadores utilizou as funções copiar e colar do Microsoft Word para enunciar todos os pontos fortes por ele verificados: "O trabalho está bem estruturado e contribui para o conhecimento na área". Foi o carimbo usado.

As expressões seguintes identificaram pontos fracos de trabalhos aceitos, e também podem ser considerados pontos fracos dos próprios pareceres:

"O resumo poderia ser mais direcionado".

"Oportunidade do assunto".

"Nada a considerar".

"A amostragem pode não ser significativa".

"Sem comentários".

"Foco conceitual".

"Baixa contribuição científica".

"O modelo sugere discriminações raciais".

"Poderia ser ampliada a amostra".

"Conclusão meio fraca".

Exemplos de expressões inconsistentes, tautológicas e mais algumas, incompreensíveis:

"Amostra não-relevante; não-probabilística; intencional, não podendo, assim, generalizar os resultados".

"A amostra poderia ser mais representativa e aleatória".

"Ponto Fraco: capacidade de generalização talvez prejudica em função da assimetria do mercado".

Ainda sobre os pontos fracos: $15 \%$ declararam a base teórico-conceitual; $16 \%$, a abordagem metodológica ou técnicas de pesquisa, enquanto $24 \%$ dos avaliadores indicaram pontos fracos em função dos níveis de entendimentos e conclusões expostas pelos autores. 


\subsection{Avaliações quantitativas}

Aproximadamente $10 \%$ das avaliações objetivas - notas de 1 a 5 para 10 quesitos foram expressas pela mesma nota para todas as dimensões, geralmente a nota 5 . Trata-se de homogeneidade que compromete a seriedade da avaliação do texto vez que as dimensões abrangem categorias avaliativas de naturezas distintas. Tal procedimento não permite distinção entre trabalhos, igualando-os equivocadamente.

Vinte e um por cento dos trabalhos aprovados (21 textos) tiveram diferença de pelo menos 2 pontos entre as notas médias de dois dos três pareceristas. As médias poderiam variar entre 1 e 5.

As medianas 4, 4,5, e 5 representaram $73 \%$ das 300 avaliações, significando que em 218 distribuições de notas os pareceristas atribuíram pelo menos $50 \%$ de notas 4 ou 5 a cada conjunto de dez categorias avaliativas, resultado que reforça as boas avaliações dos trabalhos aprovados.

Como se sabe, a moda é uma estatística que informa o valor mais freqüente de uma distribuição. Na Tabela 1, a seguir, se tem a distribuição das modas para todas as avaliações.

\section{Tabela 1 - Distribuição das Modas das 300 Avaliações dos Trabalhos Aprovados - 5 Congresso USP de Controladoria e Contabilidade - 2005.}

\begin{tabular}{|l|r|r|r|r|r|}
\hline Valor da Moda (notas) & 1 & 2 & 3 & 4 & 5 \\
\hline Freqüência Absoluta & 1 & 14 & 59 & 130 & 96 \\
\hline Porcentagens (\%) & 0 & 5 & 20 & 43 & 32 \\
\hline
\end{tabular}

Ou seja, $75 \%$ das avaliações quantitativas tiveram notas 4 ou 5 como avaliações mais freqüentes, indicando ótimos resultados para a grande maioria dos autores que tiveram seus textos aprovados. Chama a atenção uma distribuição com moda igual a 1 e 14 distribuições com notas modais iguais a 2, uma vez que os avaliadores que atribuíram essas baixas notas, surpreendentemente, indicaram a aceitação dos trabalhos, evidenciando contradição que compromete o processo de avaliação.

\subsection{Comparações entre as avaliações qualitativas e quantitativas}

Comparações entre as avaliações qualitativas e quantitativas auxiliam a compreensão do grau de (in)coerência dos pareceristas. Para tanto, foram selecionados casos em que houve expressiva diferença entre as notas médias de dois avaliadores de um mesmo texto. Assim é que em uma avaliação cujas notas médias foram 4,4, 2,4 e 4,4; medianas 4,5, 2 e 4, respectivamente, e modas 5,2 e 4 . Conta-se como um caso exemplar no qual o avaliador 2 não "gostou" do trabalho, apesar de aceitá-lo, e assim expressou um dos seus pontos fortes: "Na atual conjuntura o tema é atual". Pontos fracos: "O artigo fica muito confuso na sua parte 
final". Como se pode notar, trata-se de um exemplo que evidencia elementos de coerência entre as avaliações quanti e quali de um parecerista: ambas extremamente preocupantes.

Avaliando um mesmo texto, um dos pareceristas indicou como ponto fraco: "Redação ruim - muitos erros ao longo do texto, parágrafos muito longos e frases mal construídas". Outro avaliador do mesmo texto expressou, dentro dos pontos fortes: "Redação clara e objetiva". Por outro lado, em outra avaliação, um dos pareceristas ressaltou como ponto forte a metodologia clara e muito bem delineada, enquanto um outro avaliador do mesmo texto expressou, entre os pontos fracos, que a metodologia é incompatível com a proposta. Junta-se a esses casos uma situação de incoerência de um avaliador que evidenciou como pontos fortes, o tema e a metodologia. Sobre o mesmo texto, destacou como ponto fraco, a seqüência em que a metodologia apresentada não está correta.

Outro caso ilustra a medíocre coerência de um outro avaliador. Os dois pareceristas que atribuíram notas médias elevadas ao texto (5 e 4,3) assim enunciaram seus pontos fortes: "Ótimo trabalho. Metodologia adequada e tecnicamente consistente". "Boa estruturação do trabalho. Abordagem quantitativa interessante". Por outro lado, o avaliador que "não gostou" atribuiu nota média 2,9, e assim, de maneira inteligível, se expressou quanto aos pontos fracos: "Capacidade de generalização talvez prejudica em função da assimetria de mercado".

Reforçando a discutível tese da coerência dos pareceristas, temos mais um caso em que um avaliador que atribuiu a menor e a mais discrepante nota média e dessa maneira expressou suas opiniões quanto aos pontos fracos: o resumo sugere e menciona 'pesquisas empíricas' para afirmar conclusões do estudo, ao mesmo tempo em que utiliza uma abordagem argumentativa ao longo do estudo". Por certo, tal indecifrável mensagem em nada contribuiu aos autores do texto.

A seguir, são colocadas as avaliações de um mesmo texto realizadas por três doutores avaliadores. É lamentável o trabalho dos professores.

"Avaliador 1 - Pontos Fortes: Aplicação do ABC na avaliação de contratos. Pontos Fracos. Não deixar clara se foi uma pesquisa empírica. Status: Deve ser aceito".

Avaliador 2 - Pontos Fortes: A pesquisa está bem estruturada. Vale-se de um exemplo, um estudo de caso. Pontos Fracos: O estudo de caso é limitado a uma empresa. Status: Deve ser aceito.

Avaliador 3 - Pontos Fortes: Não há. Pontos Fracos: Assunto `batido`, sem novidades, mal escrito etc. Status: Deve ser aceito.”“.

\section{CONSIDERAÇÕES FINAIS}

Estudos sobre a produção científica - investigações epistemológicas - devem continuar como forma de se apresentar, descrever e discutir a qualidade das pesquisas sobre 
Ciências Contábeis. Acredita-se que esse esforço pioneiro de pesquisa - avaliação das avaliações de textos científicos -, passível de questionamentos, reformulações e aprimoramentos, tenha chamado a atenção, levantando debates e apresentado sugestões para a superação de insuficiências e vieses identificados na análise e na avaliação de trabalhos científicos realizada pelos professores e pesquisadores que integraram a comissão avaliadora do $5^{\circ}$. Congresso USP de Controladoria e Contabilidade, bem como contribuído para as editorias de periódicos e coordenadores de publicações científicas.

As avaliações qualitativas dos pareceristas são lacônicas, telegráficas, tanto quando expressam pontos fortes ou quando manifestam pontos fracos dos textos. São raros os comentários que tratam do conteúdo intrínseco do artigo. A maioria das avaliações restringese a considerações acessórias sobre aspectos de redação, da gramática, da formatação, da edição do trabalho, bem como do reconhecimento sobre a importância e a oportunidade de se abordar determinado tema. É expressiva a proporção de trabalhos empírico-teóricos, reafirmando a forte tendência de predominância dessa abordagem metodológica nos estudos sobre Contabilidade e Controladoria.

Preocupante constatação: a maioria dos trabalhos foi aprovada pelo cumprimento de critérios obrigatórios e necessários para qualquer texto cujo autor pretenda qualificar como científico - redação correta, atenção às regras de formatação, estrutura e organização e quesitos assemelhados.

As contradições, as imprecisões, a falta de clareza e as inconsistências de muitas avaliações evidenciam despreparo e pouco compromisso dos avaliadores em relação aos pareceres solicitados.

Quando se observam as notas atribuídas aos textos, constatam-se elevados escores: em $73 \%$ das avaliações observaram-se notas medianas iguais ou superiores a 4,0, enquanto a moda de todas as notas também alcançou 4,0 , sendo que $75 \%$ das avaliações tiveram notas 4,0 ou 5,0 como notas mais freqüentes.

Quando se comparam as avaliações qualitativas e quantitativas, notam-se consistências de critérios: nos casos de elogios quanto aos pontos fortes, encontram-se elevadas notas. Por outro lado, notas baixas são acompanhadas, geralmente, de pareceres confusos.

Estudos dessa natureza devem ser realizados constantemente. Assim como, continuamente, buscamos conhecer a realidade pela condução de pesquisas científicas, devemos sempre perseguir elevados padrões de avaliação. Como diz Bertero (2005):

Realisticamente a solução para o problema das avaliações é o mesmo que se adota para todas as soluções democráticas. O sistema será melhorado quando a crítica for seguida também de iniciativas para participar do processo com o propósito de aprimorá-lo. Quando se fala num processo de avaliação anônima por pares, os que atuam como avaliadores estão a prestar anônima e discretamente um serviço à comunidade. A melhoria do processo de avaliação é necessariamente gradual e pressupõe o envolvimento de todos e especialmente daqueles que melhor percebem as falhas do sistema. 
Não deve ser entendido como censura, mas como busca da melhoria da qualidade dos textos científicos sobre Contabilidade e Controladoria - é preciso avaliar os avaliadores e, se possível, compensá-los.

\section{REFERÊNCIAS}

BERTERO, Carlos Osmar. Mensagem da Presidência. Seção Opinião do site da ANPAD. 2005.

CHIZZOTTI, Antonio. Pesquisas em ciências humanas e sociais. 2. ed. São Paulo: Cortez, 1998.

DEMO, Pedro. Metodologia da pesquisa científica. São Paulo: Atlas, 2000.

MARTINS, Gilberto de Andrade. LINTZ, Alexandre. Guia para elaboração de monografias e trabalhos de conclusão de curso. São Paulo: Atlas, 2000.

MARTINS, Gilberto de Andrade. Análise do referencial bibliográfico de teses e dissertações sobre Contabilidade e Controladoria. $3^{\circ}$ Congresso USP de Controladoria e Contabilidade. São Paulo, FEA/USP. 2003.

QUINTELLA, Rogério H. Ética e sistematização da avaliação de trabalhos científicos. Seção Opinião do site da ANPAD. 2005.

SANTANA, Cláudio Moreira. Produção do conhecimento em contabilidade social no Brasil (1990 a 2003): abordagem bibliométrica. São Paulo, 2004. 292p. Dissertação (Mestrado)

- Departamento de Contabilidade e Atuaria da Faculdade de Economia, Administração e Contabilidade da Universidade de São Paulo.

SEVERINO, Antonio Joaquim. Metodologia do trabalho científico: diretrizes para o trabalho científico-didático na universidade. 5.ed. São Paulo: Cortez \& Moraes, 1980.

THEÓPHILO, Carlos Renato. Uma abordagem epistemológica da pesquisa em Contabilidade. São Paulo, 2000. 131p. Dissertação (Mestrado) - Departamento de Contabilidade e Atuária da Faculdade de Economia, Administração e Contabilidade da Universidade de São Paulo.

THEÓPHILO, Carlos Renato. Pesquisa em contabilidade no Brasil: Uma análise crítico-epistemológica. 2004. 212p. Tese (Doutorado) - Departamento de Contabilidade e Atuária da Faculdade de Economia, Administração e Contabilidade da Universidade de São Paulo.

TONELLI, Maria José. A arte de avaliar textos científicos. Anotações publicadas no site da Escola de Administração de Empresas de São Paulo, FGV. 2005. 